\title{
A PRÁTICA PEDAGÓGICA DO ENSINO DE EDUCAÇÃO AMBIENTAL NAS ESCOLAS PÚBLICAS URBANAS DE ARAGUATINS (TO)
}

Thiago de Loiola Araújo e Silva ${ }^{1}$

Resumo: O Presente trabalho analisa a prática pedagógica da Educação Ambiental no município de Araguatins, extremo norte do Estado do Tocantins. A pesquisa objetivou discutir a aplicação da Educação Ambiental na rede escolar municipal e estadual e também como a comunidade escolar busca incentivar as pessoas a se interessarem pelos problemas ambientais, políticos e socioculturais, não somente sensibilizando, mas modificando atitudes e proporcionando novos conhecimentos e critérios tendo este como um grande objetivo da educação, tal como se declara nos PCN's. A Educação Ambiental constitui numa forma abrangente de Educação, que se propõe atingir todos os cidadãos, através de um processo pedagógico participativo permanente que procura despertar no educando uma consciência crítica sobre a problemática ambiental, compreendendo-se como crítica a capacidade de captar a gênese e a evolução de problemas ambientais. O tema é abrangente e pode ser trabalhado com facilidade na interdisciplinaridade escolar. De natureza exploratóriodescritiva, este estudo foi estruturado a partir de uma abordagem quantitativa de dados coletados através da aplicação de questionários à 100 professores das 11 escolas do perímetro urbano de Araguatins. Os dados obtidos permitiram uma análise sobre o grau de conhecimento acerca da Educação Ambiental e sua aplicabilidade nas escolas. Os resultados obtidos demonstraram um alto nível conhecimento dos entrevistados, entretanto, reflete também o grande problema da Educação Ambiental nas escolas brasileiras: a ausência de conhecimento especifico sobre o tema e a falta de apoio das escolas, seja estrutural ou na capacitação dos professores. Os quesitos que se destacaram recaem sobre a aplicabilidade da Educação Ambiental dentro da sala de aula onde $56 \%$ dos professores afirmaram que só entram no assunto uma vez por semana. Também se destacaram a falta de programas dentro das instituições, onde $42 \%$ dos professores não tem conhecimento, 18\% não conhecem a inter-relação da Educação Ambiental com as disciplinas ministradas.

Palavras-chave: Educação Ambiental; Sustentabilidade; Comunidade Escolar.

\footnotetext{
1'nstituto Federal de Educação do Tocantins - Campus Araguatins. E-mail: thiagolaas@ifto.edu.br.
} 


\section{Introdução}

O tema Educação Ambiental foi levantado com objetivo de analisar o teor das práticas de ensino do tema em questão, para averiguar se nas escolas, o mesmo está de acordo com os Parâmetros Curriculares Nacionais(PCN's) ou se simplesmente não saiu do papel, como mera meta a ser alcançada.

Essa pesquisa tornar-se-á conveniente para evidenciar as melhorias que poderão ocorrer nas escolas públicas urbanas (07 escolas estaduais e 04 escolas municipais) de Araguatins- TO e se realmente estão sendo colocadas em prática as referências de ensino que estão descriminados nos Parâmetros Curriculares Nacionais (PCN's). Este por sua vez não possui caráter obrigatório como disciplina especifica, mas pressupõem-se suas adaptações às necessidades das escolas locais, para que se possa qualificar o ensino, trazendo melhores resultados, sendo um fator de transformação de objetivos, conteúdos e uma nova didática de ensino.

Portanto, a elaboração desta pesquisa fez um diagnóstico da proposta pedagógica nas escolas, propondo assim, uma análise do tipo de educação oferecida, se está sendo feito uma transmissão do conhecimento e encaminhando o aluno rumo à aprendizagem, pois a escola deve ter esse papel social.

Diante disso, pergunta-se: As escolas públicas de Araguatins- TO aplicam a Educação Ambiental conforme os Parâmetros Curriculares Nacionais (PCN's) e a Lei de Educação Ambiental?

Assim a questão visa levantar uma discussão sobre a prática, métodos e grau de importância que se dão nas escolas do município de Araguatins sobre a degradação do meio ambiente, ensinando os alunos a não serem somente espectadores assistindo a extinção do seu patrimônio natural.

Especialistas defendem a Educação Ambiental como um processo transversal por estar presente em todas as matérias do ano letivo dos estudantes e por desenvolver assuntos que estão presentes nas empresas, nas instituições e na realidade comum a todos (REBOUÇAS, 2014).

A Educação Ambiental surge, então, como um esforço pedagógico de articular conhecimentos, metodologias e práticas ditadas pelo paradigma da sustentabilidade. Ela pode ser vista como a estratégia inicial para um novo conceito da visão homem-natureza ou crescimento aliado à preservação. Através do exercício da Educação Ambiental o aluno vai perceber o que realmente faz diferença para aprimorar o ambiente físico ao seu derredor (MATSUSHIMA, 1991).

Dessa forma, a Educação Ambiental se torna uma ferramenta de mudança de mentalidade e da visão do homem sobre o meio ambiente. Segundo Marques (1993), o trabalho de Educação Ambiental será mais efetivo se for baseado em formas de percepção do meio ambiente. Ou seja, o ator 
ambiental deve conhecer intimamente o meio ambiente e sua forma de funcionamento no nível em que se convive.

Portanto, o objetivo deste trabalho é analisar o ensino pedagógico da Educação Ambiental nas escolas públicas do município de Araguatins - TO. Assim se faz necessário verificar se a Educação Ambiental é aplicada de acordo com a lei 9.795/99 e os Parâmetros Curriculares Nacionais, além de descrever a forma como a Educação Ambiental é aplicada no ensino dessas escolas e observar como ocorre a prática da Educação Ambiental nas escolas públicas de Araguatins (TO).

\section{Procedimentos metodológicos}

O município de Araguatins é sexto maior município do Tocantins em termos populacionais, com 31.323 habitantes (IBGE, 2010) e ocupa uma área de $2.627 \mathrm{~km}^{2}$. Localizada na região conhecida como Bico do Papagaio, fica a $621 \mathrm{~km}$ de Palmas, Capital do Estado, estando a uma altitude de 103 metros situada às margens do rio Araguaia.

O trabalho de campo teve início em dois de fevereiro de dois mil e quinze, momento em que se realizaram as primeiras visitas às escolas e também a aplicação dos questionários.

Foram aplicados 100 questionários para 100 professores, representando $35,8 \%$ dos professores dessas unidades escolares - 11 escolas no total, sendo sete Estaduais e quatro Municipais (Tabela 1).

Tabela 1: Escolas Estaduais e Municipais de Araguatins (TO).

\begin{tabular}{|c|c|c|}
\hline Escolas Estaduais & Alunos & Professores \\
\hline Escola A & 614 & 23 \\
\hline Escola B & 880 & 34 \\
\hline Escola C & 963 & 33 \\
\hline Escola D & 722 & 28 \\
\hline Escola E & 241 & 13 \\
\hline Escola F & 519 & 20 \\
\hline Escola G & 303 & 13 \\
\hline Escolas Municipais & Alunos & Professores \\
\hline Escola A' & 970 & 58 \\
\hline Escola B' & 728 & 44 \\
\hline Escola C' & 145 & - \\
\hline Escola D' & 276 & 13 \\
\hline
\end{tabular}

Fonte: Autor

Ressalta-se que todos os docentes residem na área urbana de Araguatins e também, todos se dispuseram a participar da pesquisa.

Foram elaboradas apenas perguntas fechadas em todas as escolas da zona urbana municipal para os 100 professores de todas as áreas. Dentre as 
questões abordadas estão a frequência que essa questão é levantada e a forma com que os outros professores também trabalham esse tema e a maneira que é abordado para conhecimento e entendimento dos alunos.

Foi utilizada a pesquisa exploratória - explicativa, uma vez que foi analisado o fenômeno estudado, os seus "porquês" e seus determinantes (GIL, 2010).

No modo de aplicação pelo tipo de pergunta fechada, as respostas são seguras e preestabelecidas, o que trouxe vantagens para o entrevistado, auxiliando no preenchimento de todas as respostas (GIL, 2010). No questionário com perguntas fechadas houve entre outras vantagens, menos possibilidade de desistência ou respostas por fazer. Além disso, ficou mais fácil solucionar eventuais dúvidas que os entrevistados tiveram. A pesquisa foi dividida em duas fases: visita às escolas para a aplicação de questionários e a tabulação dos dados em planilhas, utilizando a Microsoft Excel 2010.

$\mathrm{Na}$ escolha do questionário levou-se em consideração a sua objetividade, o que ajudou a obter os resultados exatos. É importante ressaltar que o anonimato professores foi preservado.

Os dados obtidos foram analisados e quantificados em formas de gráficos construídos a partir do software Microsoft Excel 2010.

Ao término da pesquisa as informações coletadas passaram por três processos de tratamento, a saber:

1. Seleção: Processo de avaliação dos dados onde foram identificados aqueles pontos relevantes para a pesquisa ou a falta destes. Nesta etapa não se fez necessário retornar ao campo, pois os dados coletados foram todos aproveitados.

2. Codificação: Nesta etapa os dados foram classificados e identificados o que proporcionou melhor quantificação e comunicação;

3. Tabulação: Foram gerados gráficos em software específico facilitando assim o entendimento dos resultados e sua análise.

Os dados coletados na pesquisa foram feitos pelo método estatístico, que por sua natureza conduz a uma análise quantitativa (GIL, 2010: 50), o que permitiu a tabulação dos dados. Considera-se de suma importância a unificação dos dados empíricos e bibliográficos para melhor entendimento das técnicas dispostas sobre a Educação Ambiental nas escolas.

\section{Resultados}

O primeiro passo para a integração com os professores da rede de ensino foi o contato com a Secretaria Municipal de Educação de Araguatins e com a Delegacia Regional de Ensino que representa a Secretaria Estadual de Educação do Tocantins. De maneira geral, esse primeiro momento foi de grande aceitação para a realização da pesquisa, não existindo nenhuma objeção por parte dos gestores na execução da mesma. 
Nas visitas de campo e na aplicação dos questionários observou-se a mesma situação, com a gestão das escolas dando apoio à realização da pesquisa e com adesão de $100 \%$ dos professores no preenchimento dos questionários.

\section{Conhecimentos e práticas sobre Educação Ambiental}

No Gráfico 1, foi questionado se os professores buscam destacar o tema Educação Ambiental na sala de aula: 93\% afirmaram que estão sempre trabalhando este tema na sala de aula e 7\% responderam que não. É importante destacar que cabe aos professores formularem, orientarem ou desenvolverem programas de Educação Ambiental a partir de várias temáticas ou lições extraídas das experiências desenvolvidas pelo núcleo de Educação Ambiental que ajuda o educador a atuar em processos sociais complexos, decorrentes de intervenções que modificam a qualidade do meio ambiente.

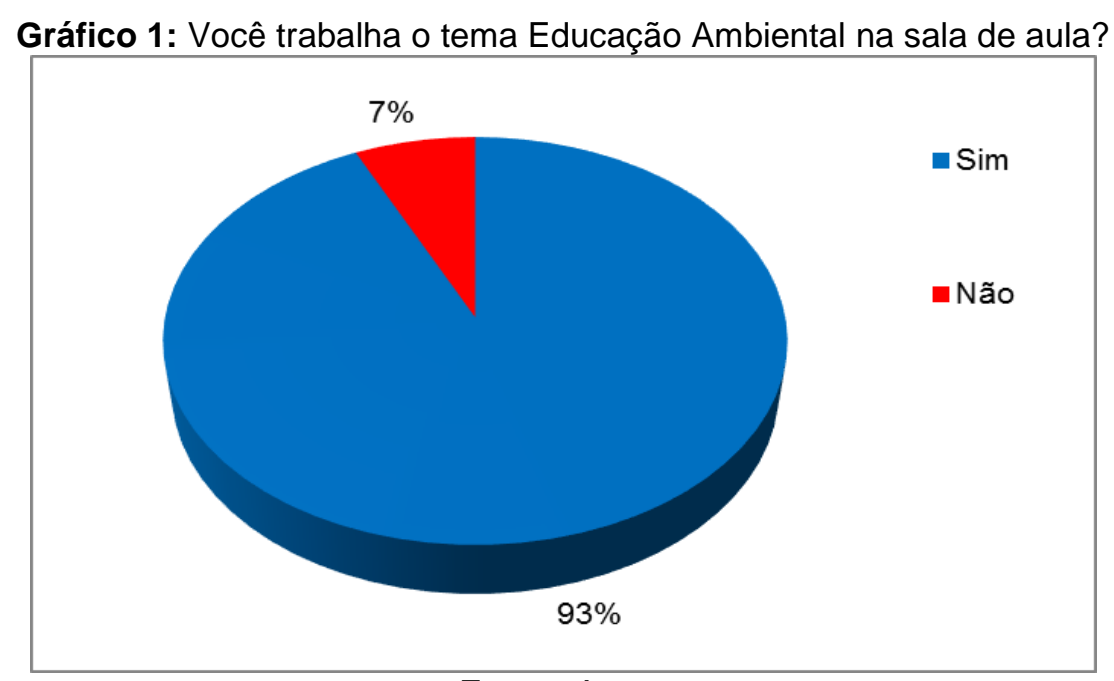

Fonte: Autor.

Bezerra (2007) encontrou resultados diferentes em trabalho desenvolvido em uma escola na região rural Vitória do Santo Antão - PE. Na pesquisa, foi diagnosticado que $52 \%$ dos professores abordam a Educação Ambiental em seus conteúdos. A diferença pode ser o perfil das escolas pesquisadas em Araguatins e em Vitória do Santa Antão: enquanto nesta existe o perfil técnico - profissional, em Araguatins foram abordadas escolas que abordam apenas o ensino médio e o fundamental.

O Gráfico 2 mostra que nas escolas é usada a típica opção de passagem de conteúdos da educação formal (48\%), mostrando assim que as instituições não seguem as orientações dos PCN's, de terem em sua metodologia o tema Educação Ambiental transversalmente por todas as disciplinas e áreas. Há ainda $32 \%$ que utilizam debates como forma de incentivar o pensamento crítico dos alunos; $28 \%$ fazem isso em forma de brincadeiras, com o objetivo de atrair os alunos com o tema e $12 \%$ dos professores abordam o assunto de outras formas. 
Gráfico 2: Como você desenvolve na prática o Ensino de Educação Ambiental?

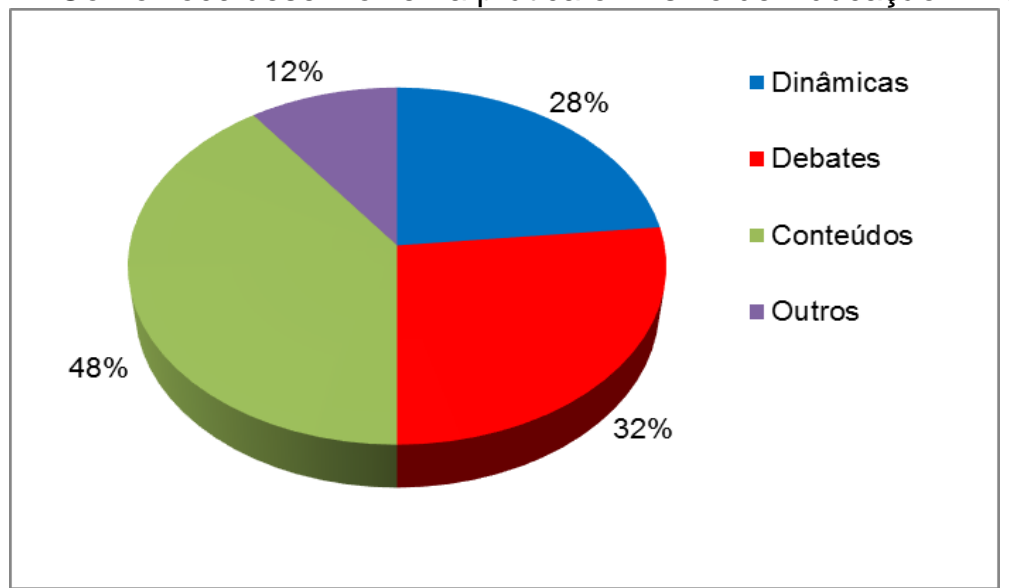

Fonte: Autor.

No Gráfico 3 observa-se que $56 \%$ dos entrevistados abordam o tema Educação Ambiental apenas uma vez por semana; $18 \%$ dos professores entrevistados responderam duas vezes; $19 \%$ afirmaram que utilizam mais de duas vezes e $7 \%$ dos entrevistados disseram que não utilizam, mostrando que são poucos professores que utilizam este tema mais de duas vezes por semana.

Gráfico 3: Quantas vezes por semana você aborda a Educação Ambiental?

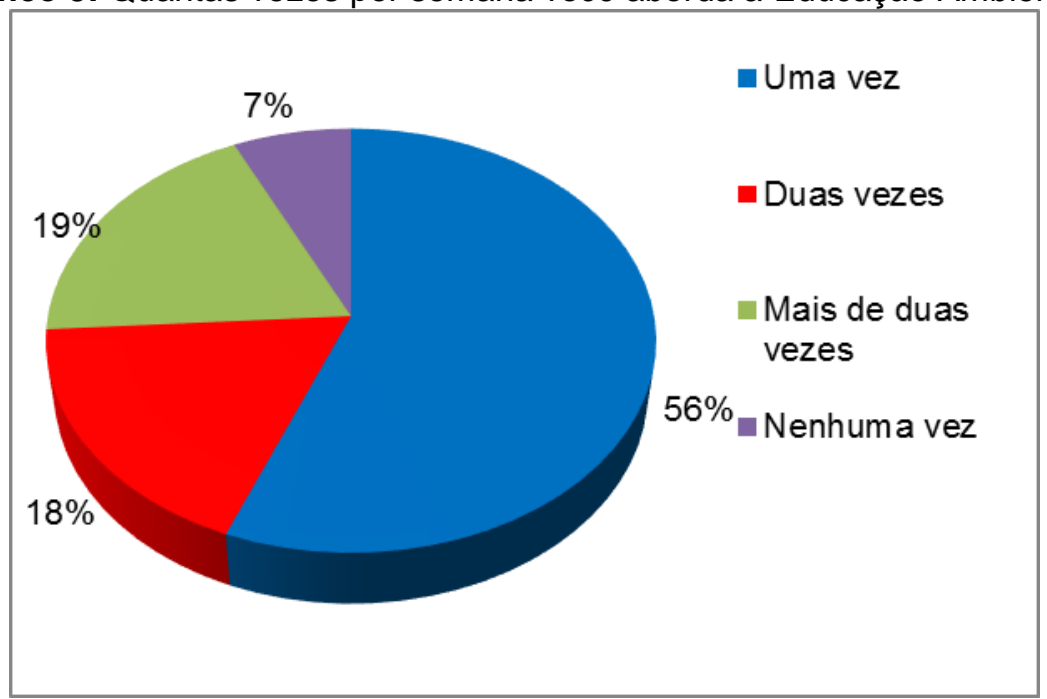

Fonte: Autor.

O Gráfico 4 destaca programas de Educação Ambiental dentro da instituição onde trabalha; $58 \%$ dos professores afirmam que existe um Programa de Educação Ambiental na escola em que trabalha; $35 \%$ dizem o contrário, não existindo nenhum programa na instituição em que atuam e há 
ainda uma minoria de $7 \%$ que não sabem. Mostrando assim que as Secretarias de Educação do Município e do Estado estão preocupadas com a questão. No entanto, e válido destacar que qualquer tipo de informação trabalhada dentro da Educação Ambiental pode ter diferentes níveis. Um programa ou mesmo um processo educativo onde a base dos conteúdos que são aplicados estão diretamente ligados com a preservação ambiental deve ser nivelado e igualado em todas as instituições para que todos falem a "a mesma língua", objetivando a melhoria na qualidade de vida das pessoas.

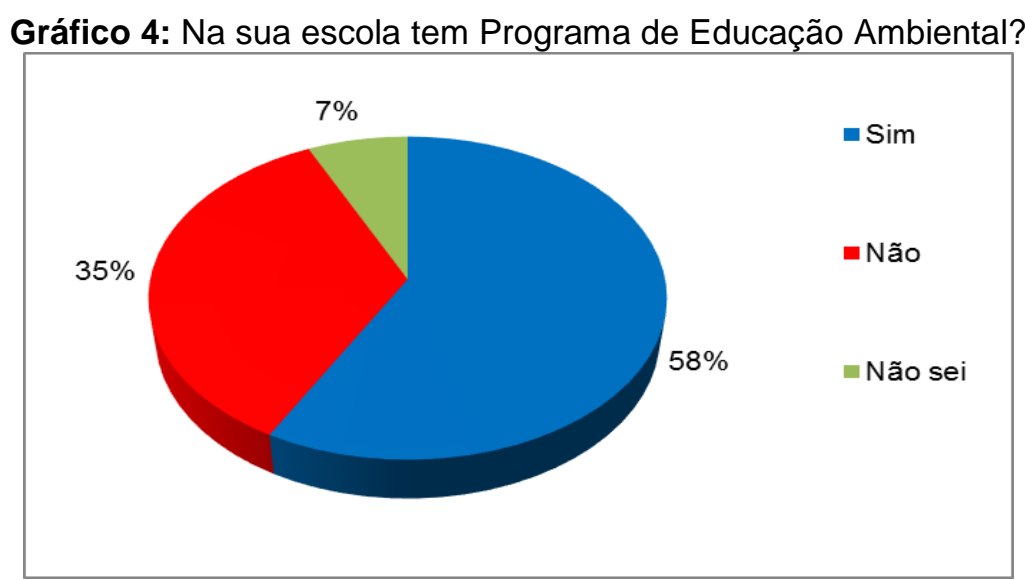

Fonte: Autor.

Segundo Bezerra (2007, p.122),

a relação entre Educação Ambiental e meio ambiente deve ser alvo de esforços por parte de entidades governamentais e nãogovernamentais que visem ações educativas formais e informais relativas a tais temas. Em outras palavras, os esforços deveriam ser direcionados no sentido de que seja compreendido que a Educação Ambiental é, de fato, uma subárea para estudos relacionados ao meio ambiente.

O Gráfico 5 demonstra se existe a interação entre os professores sobre aplicabilidade da Educação Ambiental dentro da escola: 89\% dos professores responderam que conhecem colegas que costumam relacionar ações de preservação do meio ambiente no seu cotidiano e $11 \%$ não conhece, ou seja, a maioria dos educadores diz ter conhecimento de colegas que praticam as questões ambientais. Essa prática acontece com o incentivo dos gestores. Entretanto, não há uma interação com os profissionais da área pedagógica, mostrando a fragilidade no projeto político pedagógico. 
Gráfico 5: Você tem conhecimento de outros colegas que praticam Educação Ambiental?

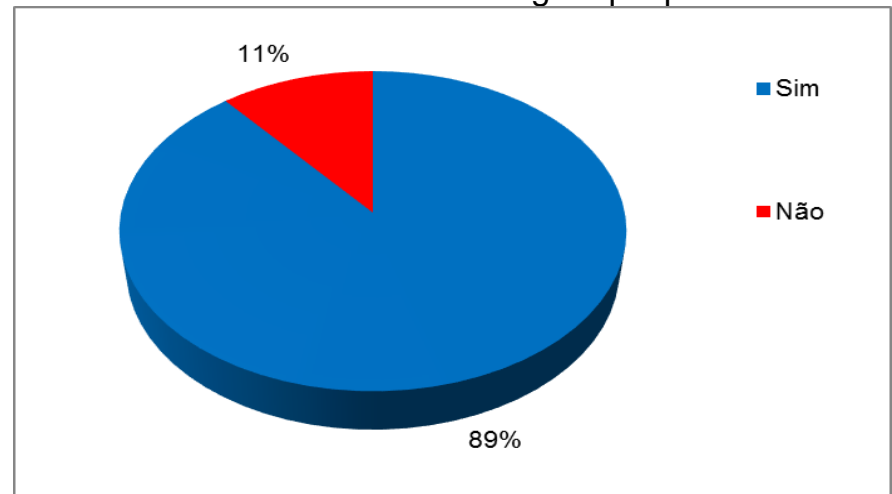

Fonte: Autor.

Para os professores que não possuem o hábito da Educação Ambiental, seja de forma interdisciplinar ou não, um programa voltado para a área ambiental que vise a formação docente e a produção de novas propostas curriculares poderá sanar essa deficiência, além de estimular a participação não apenas dos professores, mas sim de toda a comunidade escolar. Com isso, a incorporação da temática ambiental nos currículos escolares será realizada de forma mais coerente e de acordo com a realidade de cada comunidade (TABANEZ, 2000).

No Gráfico 6 foi questionado se a disciplina em que o professor leciona pode-se relacionar com a Educação Ambiental: $82 \%$ dos professores entrevistados afirmaram que podem aplicar a Educação Ambiental com seu conteúdo diário sem nenhum problema; $18 \%$ responderam que não. No entanto o recurso pedagógico utilizado para tal finalidade deve ser o exercício de percepção ambiental reflexivo, acompanhado do enfrentamento das questões que emergem desta atividade (ROCHA, 2002).

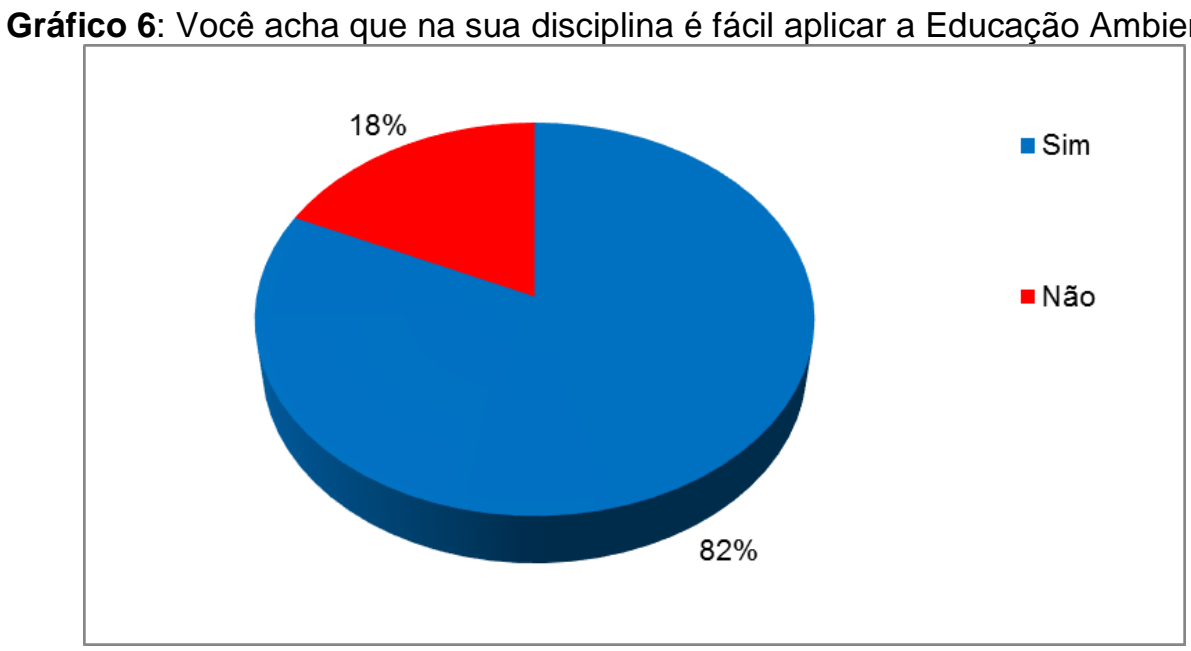

Fonte: Autor. 
Lucatto e Talamoni (2007) em trabalho realizado sobre interdisciplinaridade na Educação Ambiental contatou que, apesar das leis, debates e promulgações nacionais e internacionais, a Educação Ambiental ainda é aplicada esporadicamente e de forma tradicional, sem a existência de qualquer articulação com as disciplinas escolares, por professores e órgãos envolvidos na área de meio ambiente.

O Gráfico 7 teve o intuito de averiguar se os professores pesquisados acreditam que o ensino da Educação Ambiental tem mostrado bons resultados em relação ao meio em que vive: $45 \%$ dos entrevistados destacaram que sim, é visível um melhoramento entre os discentes em relação aos cuidados com o ambiente; $1 \%$ respondeu que não e $54 \%$ dos entrevistados relataram que é necessário melhorar ainda os métodos para serem mais eficientes. As mudanças sociais e econômicas em um país provocam a criação de novas práticas culturais que vem responder às questões colocadas pelas novas circunstâncias, embora seja visto que essas mudanças precisam ser trabalhadas de forma continua.

Gráfico 7: Você acredita que os métodos utilizados para o ensino de Educação Ambiental conseguem ter um bom desempenho?

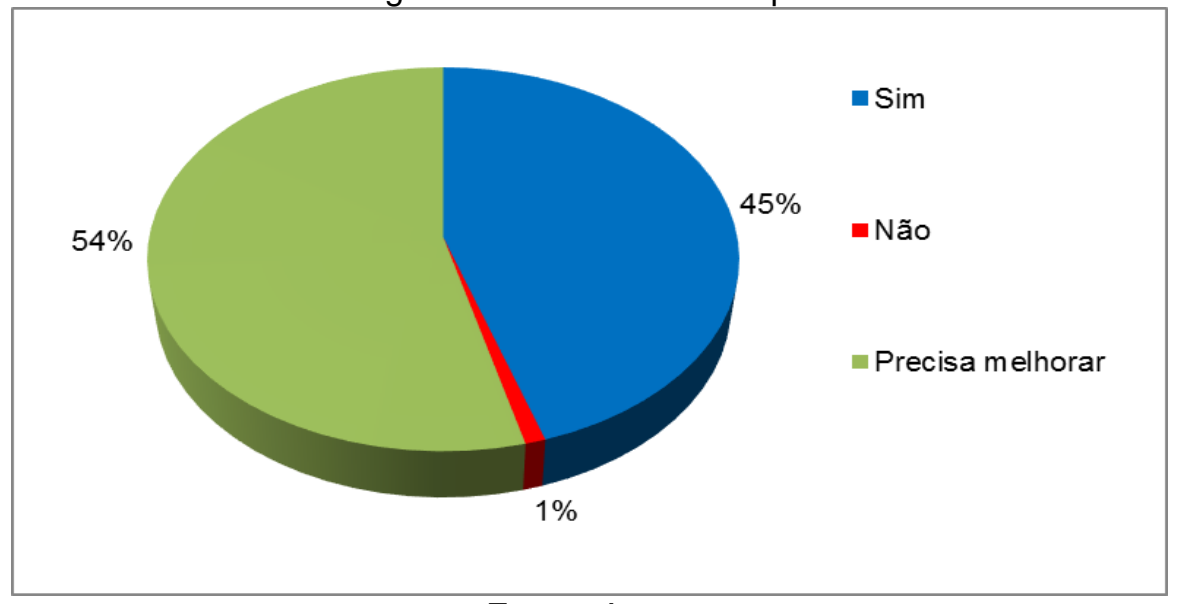

Fonte: Autor.

A ausência do conhecimento sobre Educação Ambiental e também sobre novas formas de aplicação do conhecimento foram as justificativas apresentadas pelos docentes que responderam "não" ou "precisa melhorar". Gonçalves (2007, p. 20) observou resultados semelhantes, afirmando que possivelmente isso se dá devido à dependência do livro didático como principal fonte de informação e de aplicação de atividades. Para a autora, o livro didático atual como "tábua de salvação" quanto aos temas de ciências e Educação Ambiental.

Uma das formas mais citadas de aplicação da Educação Ambiental pelos professores que verificaram um aumento de rendimento nos alunos foram as aulas de campo. Segundo algumas citações dos professores, na aula de campo o aluno sente na prática a questão ambiental e como o meio 
ambiente está degradado. Existe maior interesse por sair da rotina da sala de aula e da interação com os colegas de classe. Seniciato e Cavasan (2004), afirma que o bem-estar sentido pelos alunos durante a aula de campo torna agradável o processo ensino - aprendizagem, contribuindo para o aprendizado de novos assuntos.

Para melhor entendimento sobre a conscientização dos alunos quando administrado a Educação Ambiental no seu dia-a-dia, houve uma divisão nas respostas: $28 \%$ destacaram como regular; $53 \%$ dos professores afirmaram que os alunos tiveram um bom interesse em relação ao tema e 19\% responderam que foi ótimo (Gráfico 8).

Gráfico 8: Como você avalia o interesse de seus alunos ao final de cada aula quando se envolve a Educação Ambiental?

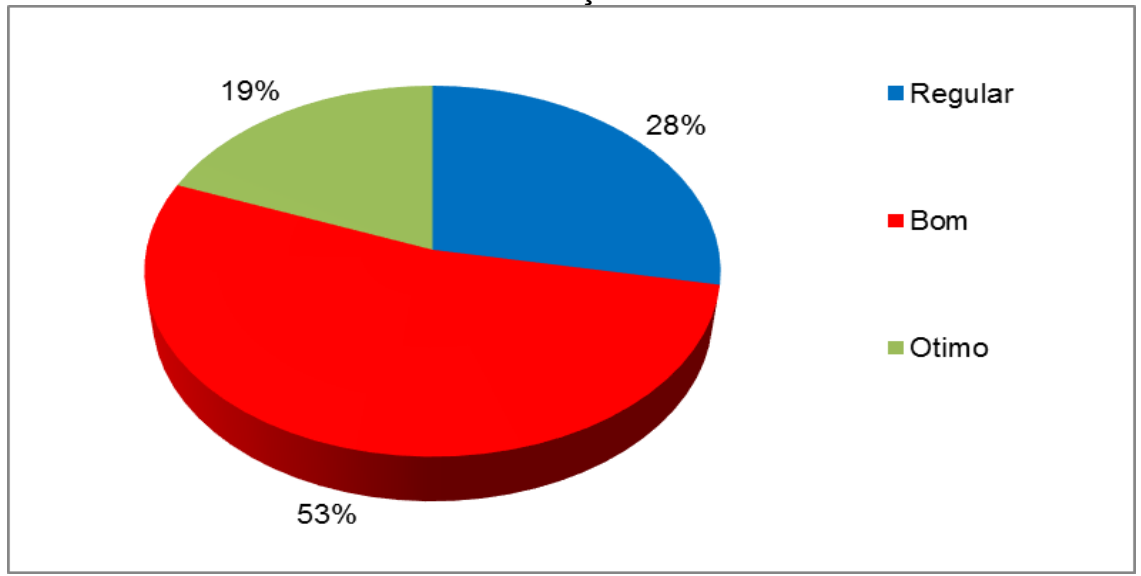

Fonte: Autor.

Com base nas respostas dos docentes, foi possível identificar três comportamentos dos alunos após as aulas abordarem os conteúdos sobre a questão ambiental: uma maior inserção do tema em outras disciplinas que não são necessariamente ou comumente ligadas ao meio ambiente; um aumento maior de questionamentos sobre o tema durante as aulas de biologia do ensino médio e/ou de ciências no ensino fundamental; a inserção do tema através de exemplos observados no convívio doméstico ou no bairro onde residem.

Por fim, o Gráfico 9 apresenta os resultados do questionamento sobre o auxilio da unidade escolar na ajuda na formação da opinião dos alunos sobre o meio ambiente: $93 \%$ dos entrevistados responderam que a escola sem dúvida alguma tem um importante papel nas articulações de ações educativas voltadas para a preservação do meio ambiente, onde a mesma se mostra como um espaço mais indicado e privilegiado para que haja implementações dessas atividades, uma vez que, através da Educação Ambiental, deve levar o aluno a buscar valores que conduzam a uma convivência harmoniosa com o ambiente. 
Gráfico 9: Pode-se afirmar que as escolas ajudam na formação da opinião dos alunos sobre o meio ambiente?

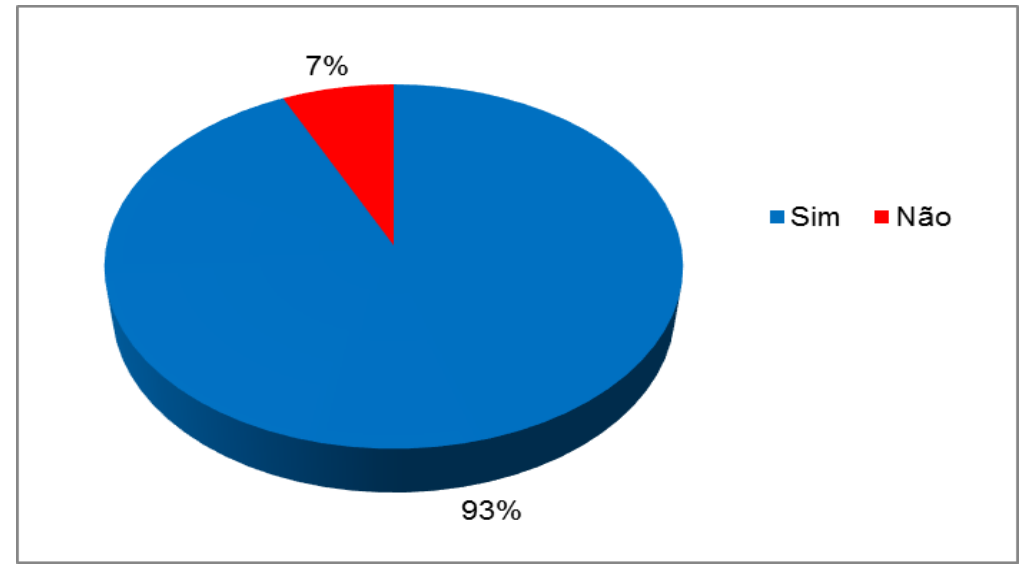

Fonte: Autor.

É notória a importância da escola no desenvolvimento e implemento de ações voltadas para Educação Ambiental. Apesar de outros órgãos abarcarem a Educação Ambiental como pilar estrutural (ONG's, órgão ambientais), é na escola que o aluno encontra o local mais propicio para a absorção desse conhecimento.

Para Seniciato e Cavasan (2004), isso se manifesta principalmente através das interações sociais entre os alunos e a comunidade escolar (professores, diretores) e entre os próprios alunos. Relações sociais estas sentidas na forma como pensam os alunos e na forma dos professores conduzirem o aprendizado com o apoio da unidade escolar.

\section{Considerações finais}

Os resultados obtidos a partir da análise dos dados da presente pesquisa mostram que os docentes das rede municipal e estadual de ensino de Araguatins sofrem do mesmo mal que assola a grande maioria das escolas brasileiras quanto à Educação Ambiental: a falta de apoio, seja ele financeiro ou estrutural e também a ausência mais profunda quanto aos conceitos e conhecimentos sobre a interdisciplinaridade para a aplicação da Educação Ambiental.

Para sanar uma parte do problema, é necessária a capacitação ou oficinas de Educação Ambiental no sentido de ampliarem sua concepção sobre os termos. Nas palavras de Bezerra (2007),

uma vez que as abordagens conceituais do meio ambiente e da Educação Ambiental não devem estar restritas à dimensão ecológica, mas associada à uma visão contextualizada da realidade ambiental, a capacitação para se tratar da problemática ambiental deve também abranger efetivamente os aspectos sócio - econômicos e culturais. 
Entretanto, é notório que os resultados demonstram um processo de transição entre o senso comum - aplicação da disciplina "crua" - para uma interdisciplinaridade, onde o tema meio ambiente já é citado no dia a dia da sala de aula.

Deve-se ressaltar que a inserção no currículo escolar da temática meio ambiente envolve uma visão crítica e sistêmica da complexidade da problemática ambiental. Situação que ainda dá os primeiros passos nas escolas de Araguatins e que para se concretizar, como já foi citado, deve-se transpor uma série de obstáculos.

Por fim, foi identificada a necessidade de se trabalhar intensamente com os docentes na intenção de se tornarem e formarem multiplicadores do conhecimento ambiental, uma vez que quando aplicados em sala de aula, os saberes ambientais são amplamente aceitos pelos alunos. Dessa forma, a representação do meio ambiente como forma de melhoria de qualidade de vida da população será mais efetiva.

Dessa forma, em médio prazo, a incorporação da Educação Ambiental nos processos curriculares ou na construção de caminhos alternativos à sala de aula acontecerá de forma natural, com os propósitos da Educação Ambiental para a sustentabilidade do planeta.

\section{Referências}

BEZERRA, T.M.O. Concepções de meio ambiente e Educação Ambiental por professores da Escola Agrotécnica Federal de Vitória de Santo AntãoPE, 2007.

BRASIL, Parâmetros Curriculares Nacionais. Tema transversais, $5 . \underline{a}$ a $8 .^{a}$ séries, 1996, p.201.

GIL, A.C. Como Elaborar Projetos de Pesquisa, São Paulo: Atlas, 2010.

IBGE. Instituto Brasileiro de Geografia e Estatística, Cidades, Censo de 2010.

KOFF, E.D. A questão ambiental e o estudo de ciência: algumas atividades. Goiânia: editora da UFG, 1995.

LUCATTO, L.G.; TALAMONI, J.L.B. A construção coletiva interdisciplinar em Educação Ambiental no ensino médio: a microbacia hidrográfica do Ribeirão dos Peixes como tema gerador. Ciência \& Educação (Bauru), v.13, n.3, 2007.

MARQUES, J.G.W. Etnoecologia, Educação Ambiental e superação da pobreza em áreas de manguezais. Anais do I Encontro Nacional de Educação Ambiental em Áreas de Manguezais, Maragogipe, Brasil, 1993, p.29-35.

MATSUSHIMA, K. Dilema contemporâneo e Educação Ambiental: uma abordagem arquetipica e holistica. Em Aberto. v.10. no 49, p. 15-33, 1991.

MEDEIROS, M.C.S.; RIBEIRO, M.C.M.; FERREIRA, C.M.A. Meio ambiente e educação ambiental nas escolas públicas. Âmbito Jurídico, Rio Grande, XIV, n. 92, set 2011.2 Disponível em: $<$ http://www.ambitojuridico.com.br/site/?n link=\%20revista artigos leitura\&artig o id=10267\&revista caderno=5>. Acesso em 28 set 2016. 
REBOUÇAS, F. Educação Ambiental. Disponível em: <www.infoescola.com> Acesso em: 12 de Out. De 2014.

SENICIATO, T.; CAVASSAN O. Aulas de campo em ambientes naturais e aprendizagem em ciências - um estudo com alunos do ensino fundamental. Ciência \& Educação, v. 10, n. 1, p. 133-147, 2004

SOUZA, R.F. Uma experiência em Educação Ambiental: formação de valores socioambientais. Dissertação de mestrado, Dezembro de 2003.

TABANEZ, M.F. Significado para professores de um programa de Educação Ambiental em unidades de conservação. Dissertação de Mestrado, Universidade Federal de São Carlos, Brasil, 2000. 